\title{
Highly Efficient and Environmentally Friendly Preparation of 14-Aryl-14H-dibenzo[a,j]xanthenes Catalyzed by Tungsto-divanado-phosphoric Acid
}

\author{
Reza TAYEBEE*, Shima TIZABI \\ Department of Chemistry, School of Sciences, Hakim Sabzevari University, Sabzevar 96179-76487, Iran
}

\begin{abstract}
A rapid and efficient procedure for the preparation of various aryl-14H-dibenzo[a,j]xanthenes was reported. The method developed produced excellent yields via one-pot condensation of $\beta$-naphthol with various aryl-aldehydes in the presence of Keggin vanadium substituted heteropolyacid, $\mathrm{H}_{5} \mathrm{PW}_{10} \mathrm{~V}_{2} \mathrm{O}_{40}$, as catalyst under solvent free conditions. The present methodology therefore offered several advantages but not limited to excellent yields ( $82 \%-98 \%)$, short reaction times (30-50 min), mild reaction conditions, simple work-up, as well as the utilization of cheap and environmentally benign catalyst in the absence of organic solvents.
\end{abstract}

Key words: xanthene; one-pot; condensation; aldehyde; $\beta$-naphthol; heteropolyacid; Keggin; solvent-free CLC number: O643 Document code: A

Received 4 January 2012. Accepted 17 February 2012.

*Corresponding author. Tel: +98-571-4410310; Fax: +98-571-4410300; E-mail: rtayebee@yahoo.com

English edition available online at Elsevier ScienceDirect (http://www.sciencedirect.com/science/journal/18722067).

Xanthene derivatives are biologically important compounds with wider biological applicability including anti-depressants, antibacterial, and antiviral agents [1]. These compounds also have antagonist activity towards paralyzing action of zoxazolamine [2] and in photodynamic therapy [3]. Because with ampicilin and chlotrimazole, xanthenediones also have potential antimicrobial activity against Staphlococcus aureus and Candida albicans [4]. Different procedures have been used to produce xanthenes and benzoxanthenes, and this includes the reaction of aryloxymagnesium halides with triethylorthoformate [5], cyclodehydration [6], intra molecular phenyl carbonyl coupling reactions of benzaldehydes and acetophenones [7], cyclization of polycyclic aryltriflate esters [8], and cyclocondensation of 2-hydroxy aromatic aldehydes with 2-tetralone [9]. However, many of the aforementioned procedures have drawbacks such as long reaction times, unsatisfactory yields, harsh reaction conditions, and excessive use of reagents and catalysts. This paper therefore reports a novel and convenient method for the production of these pharmaceutically important compounds in large quantities for utilization in testing their pharmacological activities.

Heteropoly acids are water soluble complex metal-oxo structures which have been extensively exploited as catalysts in various homogeneous and heterogeneous organic transformations in applications ranging from fine chemical industries to pharmaceuticals and food industries $[10,11]$. These compounds possess a strong Brönsted acid activity approaching the super acidic region, a region that is more potent than many mineral acids and conventional solid acids such as amorphous $\mathrm{SiO}_{2}, \mathrm{Al}_{2} \mathrm{O}_{3}, \mathrm{H}_{3} \mathrm{PO}_{4} / \mathrm{SiO}_{2}, \mathrm{HX}$, and $\mathrm{HY}$ zeolites [12]. The advantages afforded by applying Keggin-type heteropolyacids reactions include strong acidities, lower proportion of side reactions, and production of non toxic wastes. Following the diverse applications of heteropolyacids in organic synthesis, we have extended their excellent catalytic applications in the preparation of bis-indolyl-methanes [13], acetylation of alcohols [14], Biginelli reaction [15], oxidation of aromatic amines [16], and tetrahydropyranylation of alcohols [17]. The use of heteropolyacids, as catalysts for fine organic synthetic processes, is to develop and synthesize antioxidants, medicinal preparations, vitamins, and biologically active substances as reported previously [18].

Heteropolyacids are generally constructed from their primary, secondary, and tertiary building blocks. The primary unit, which is the most common, is a thermally stable poly nuclear structure, and is known as Keggin unit. The catalytic function of the Keggin category has attracted much attention among heteropoly compounds synthesis. They have the general formula $\mathrm{L}_{8-\mathrm{x}} \mathrm{XM}_{12} \mathrm{O}_{40}$, where $\mathrm{L}$ is a counter cation (proton, Group I and II metals, and transition metals with the oxidation state $x$ ), $\mathrm{X}$ is a heteroatom such as $\mathrm{P}^{5+}$, $\mathrm{Si}^{4+}$, etc. which is functioned as central atom in a tetrahedral arrangement of oxygen atoms surrounded by 12 oxygens in a octahedra shape including the addenda atoms, and $\mathrm{M}$ is 
the addenda atom (most commonly $\mathrm{Mo}^{6+}$ or $\mathrm{W}^{6+}$ ). Accordingly, the oxygen atoms in the Keggin unit can be classified as a central oxygen atoms, two types of bridging oxygen atoms, and terminal oxygen atoms $[19,20]$. Therefore, the Keggin structure is formed by a central tetrahedron $\mathrm{XO}_{4}$ surrounded by 12 octahedra of $\mathrm{MO}_{6}$. The structural properties of these compounds could provide intrigueing opportunities for the catalyst design and can be controlled by a proper choice of the polyanion.

In the current work a highly versatile, highly efficient and environmental friendly method for the synthesis of biologically active 14-substituted-14H-dibenzo[a,j] xanthene derivatives is reported. The reaction is via three-component condensation reaction of readily available starting materials, $\beta$-naphthol and aldehydes, in the presence of a catalytic amount of $\mathrm{H}_{5} \mathrm{PW}_{10} \mathrm{~V}_{2} \mathrm{O}_{40}$ as a Keggin-type vanadium substituted heteropolyacid under solvent-free condition (Scheme 1). The experimental procedure is remarkably simple, rapid, high yielding, and requires non toxic organic solvents or inert atmosphere.

\section{Experimental}

Reagents and starting materials were purchased from commercially available vendors and were used as received. All products were identified by comparison of their spectral and physical data with those previously reported. Progress of the reactions was monitored by Thin Layers Chromatography (TLC) and Infrared analysis. Infrared spectra were recorded (KBr pellets) on a 8700 Shimadzu Fourier Transform spectrophotometer. ${ }^{1} \mathrm{H}$ and ${ }^{13} \mathrm{C}$ NMR spectra were recorded on a Bruker AVANCE 300-MHz instrument using TMS as an internal reference. The catalyst $\mathrm{H}_{5} \mathrm{PW}_{10} \mathrm{~V}_{2} \mathrm{O}_{40}$ was prepared and characterized according to published procedures as follows.

\subsection{Preparation of 10-tungsto-2-vanadophosphoric acid $\mathrm{H}_{5} \mathrm{PW}_{10} \mathrm{~V}_{2} \mathrm{O}_{40} \cdot 30 \mathrm{H}_{2} \mathrm{O}$ [21]}

Sodium metavanadate $\left(\mathrm{NaVO}_{3}, 12.2 \mathrm{~g}, 100 \mathrm{mmol}\right)$ was dissolved in $50 \mathrm{ml}$ of boiling water and mixed with disodium hydrogen phosphate $\left(\mathrm{Na}_{2} \mathrm{HPO}_{4}, 3.55 \mathrm{~g}, 25 \mathrm{mmol}\right)$, already dissolved in $50 \mathrm{ml}$ of water. After the resulting solution was cooled to room temperature, concentrated sulfuric acid ( $5 \mathrm{ml}, 17 \mathrm{~mol} / \mathrm{L}, 85 \mathrm{mmol})$ was added to the mixture to

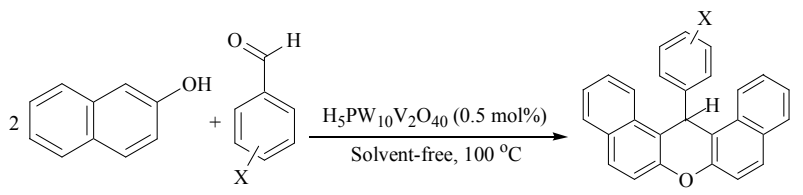

Scheme 1. The synthesis of biologically active 14-substituted-14Hdibenzo[a,j] under solvent-free condition. give a red solution. Sodium tungstate dihydrate $\left(\mathrm{Na}_{2} \mathrm{WO}_{4} \cdot 2 \mathrm{H}_{2} \mathrm{O}, 82.5 \mathrm{~g}, 250 \mathrm{mmol}\right)$ was dissolved in $100 \mathrm{ml}$ of water and added to the red solution with vigorous stirring, followed by the slow addition of concentrated sulfuric acid (42 ml, $17 \mathrm{~mol} / \mathrm{L}, 714 \mathrm{mmol})$. Extraction of the solution with diethyl ether $(500 \mathrm{ml})$, followed by evaporation in air, produced $\mathrm{H}_{5} \mathrm{PW}_{10} \mathrm{~V}_{2} \mathrm{O}_{40}$ as a crystalline, orange-red solid (yield, 74\%). Calculated (Found): P, 0.98 (1.05); W, 58.24 (58.12); V, 3.22 (3.16); $\mathrm{H}_{2} \mathrm{O}, 17.12$ (17.26). FT-IR (KBr): 1070(s), 980(vs), 885(s), 788(vs) cm $\mathrm{cm}^{-1}$.

\subsection{General procedure for the synthesis of aryl-14H-dibenzo[a,j]xanthenes}

A mixture of $\beta$-naphthol ( $2 \mathrm{mmol})$, aldehyde $(1 \mathrm{mmol})$, and $\mathrm{H}_{5} \mathrm{PW}_{10} \mathrm{~V}_{2} \mathrm{O}_{40}(1 \mathrm{~mol} \%)$ was heated to $100{ }^{\circ} \mathrm{C}$ for the appropriate time. Progress of the reaction was monitored by TLC utilizing petroleum ether and ethyl acetate with a molar ratio of 2:1 acts as mobile solvent. After completion of the reaction, the mixture was cooled and washed with $\mathrm{CHCl}_{3}(10 \mathrm{ml})$ to remove the unreacted aldehyde. Then, the solvent was evaporated and the crude product was recrystallized from ethanol to afford the corresponding pure product.

\subsection{Spectral data for selected dibenzoxanthenes $[22,23]$}

14-Phenyl-14H-dibenzo[a,j]xanthenes: Pale yellow solid; ${ }^{1} \mathrm{H} \mathrm{NMR}\left(\mathrm{CDCl}_{3}\right): \delta 8.40(\mathrm{~d}, J=8.4 \mathrm{~Hz}, 2 \mathrm{H}), 7.82(\mathrm{~d}, J=$ $7.9 \mathrm{~Hz}, 2 \mathrm{H}), 7.79(\mathrm{~d}, J=8.8 \mathrm{~Hz}, 2 \mathrm{H}), 7.58(\mathrm{t}, J=7.7 \mathrm{~Hz}$ $2 \mathrm{H}), 7.53$ (d, $J=7.5 \mathrm{~Hz}, 2 \mathrm{H}), 7.49$ (d, $J=8.8 \mathrm{~Hz}, 2 \mathrm{H}), 7.41$ $(\mathrm{t}, J=7.5 \mathrm{~Hz}, 2 \mathrm{H}), 7.15(\mathrm{t}, J=7.5 \mathrm{~Hz}, 2 \mathrm{H}), 7.00(\mathrm{t}, J=7.5$ $\mathrm{Hz}, 1 \mathrm{H}), 6.49$ (s, 1H); ${ }^{13} \mathrm{C}$ NMR: 148.7, 145.0, 131.3, 131.0, $128.8,128.5,128.1,126.8,126.5,126.3,124.2,122.6$, 117.9, 117.4, 38.2; IR (KBr, $\left.\mathrm{cm}^{-1}\right): 3068,3020,2885,1620$, 1590, 1512, 1488, 1457, 1402, 1252, 1080, 1025, 965, 825, 745, 700; EI-MS: $m / z(\%)=358\left(\mathrm{M}^{+}\right)$; Anal. Calcd for $(\%)$ $\mathrm{C}_{27} \mathrm{H}_{18} \mathrm{O}: \mathrm{C}$, 90.47; H, 5.06; Found: $\mathrm{C}, 90.41$; H, 5.14.

14-(4-Chlorophenyl)-14H-dibenzo[a,j]xanthenes: Brown solid; ${ }^{1} \mathrm{H} \mathrm{NMR}\left(\mathrm{CDCl}_{3}\right): \delta 8.29(\mathrm{~d}, J=8.46 \mathrm{~Hz}, 2 \mathrm{H})$, 7.83-7.77 (m, 4H), 7.58-7.54 (m, 2H), $7.47(\mathrm{~s}, 1 \mathrm{H})$, $7.45-7.38(\mathrm{~m}, 5 \mathrm{H}), 7.10-7.07(\mathrm{~m}, 2 \mathrm{H}), 6.44(\mathrm{~s}, 1 \mathrm{H}) ;{ }^{13} \mathrm{C}$ NMR: $156.0,147.8,132.8,131.2,129.3,128.8,128.3$, 127.0, 126.8, 126.5, 124.7, 119.3, 118.2, 117.8, 33.5; IR $\left(\mathrm{KBr}, \mathrm{cm}^{-1}\right): 3050,2925,1620,1595,1456,1431,1396$, 1242, 1060, 960, 824, 778, 695; EI-MS: $m / z(\%)=392$ $\left(\mathrm{M}^{+}\right)$; Anal. Calcd for $\mathrm{C}_{27} \mathrm{H}_{17} \mathrm{ClO}(\%)$ : C, 82.54; H, 4.36; Found: C, 82.46; H, 4.44.

14-(4-Nitrophenyl)-14H-dibenzo[a,j]xanthenes: Yellow solid; ${ }^{1} \mathrm{H}$ NMR $\left(\mathrm{CDCl}_{3}\right): \delta 8.29(2 \mathrm{H}, \mathrm{d}, J=8.4 \mathrm{~Hz}), 7.99$ $(2 \mathrm{H}, \mathrm{d}, J=8.7 \mathrm{~Hz}), 7.86(2 \mathrm{H}, \mathrm{d}, J=4.1 \mathrm{~Hz}), 7.82(2 \mathrm{H}, \mathrm{d}, J$ $=5.4 \mathrm{~Hz}), 7.67(2 \mathrm{H}, \mathrm{d}, J=8.8 \mathrm{~Hz}), 7.61(2 \mathrm{H}, \mathrm{t}, J=5.6 \mathrm{~Hz})$, $7.51(2 \mathrm{H}, \mathrm{d}, J=8.9 \mathrm{~Hz}), 7.44(2 \mathrm{H}, \mathrm{t}, J=7.9 \mathrm{~Hz}), 6.60(1 \mathrm{H}$, 
s); IR $\left(\mathrm{KBr}, \mathrm{cm}^{-1}\right): 3070,2930,1621,1591,1614,1457$, 1400, 1340, 1200, 1140, 1105, 1013, 964, 851, 827, 808, 742, 690; EI-MS: $m / z(\%)=403\left(\mathrm{M}^{+}\right)$; Anal. Calcd for $\mathrm{C}_{27} \mathrm{H}_{17} \mathrm{NO}_{3}$ (\%): C, 80.38; H, 4.25; N, 3.47; Found: C, 80.30; H, 4.35; N, 3.55 .

14-(3-Chlorophenyl)-14H-dibenzo[a,j]xanthenes: Brown solid; ${ }^{1} \mathrm{H}$ NMR $\left(\mathrm{CDCl}_{3}\right): \delta 8.30(\mathrm{~d}, J=8.4 \mathrm{~Hz}, 2 \mathrm{H}), 7.86(\mathrm{~d}$, $J=8.6 \mathrm{~Hz}, 2 \mathrm{H}), 7.76(\mathrm{~d}, J=9.0 \mathrm{~Hz}, 2 \mathrm{H}), 7.60(\mathrm{t}, J=7.0$ $\mathrm{Hz}, 2 \mathrm{H}), 7.50$ (d, $J=8.9 \mathrm{~Hz}, 2 \mathrm{H}), 7.48-7.43$ (m, 4H), 7.10 (t, $J=8.0 \mathrm{~Hz}, 1 \mathrm{H}), 6.96(\mathrm{~d}, J=8.7 \mathrm{~Hz}, 1 \mathrm{H}), 6.45(1 \mathrm{H}, \mathrm{s})$; ${ }^{13} \mathrm{C}$ NMR: $148.5,146.8,134.5,131.2,131.0,129.7,129.1$, $128.8,128.2$, 127.1, 126.8, 126.4, 124.5, 122.4, 118.1, 116.4, 37.8; IR (KBr, cm $\left.{ }^{-1}\right): 3053,2926,1622,1590,1508$, 1455, 1430, 1398, 1245, 1064, 959, 815, 775, 745, 690; EI-MS: $m / z(\%)=392\left(\mathrm{M}^{+}\right)$; Anal. Calcd for $\mathrm{C}_{27} \mathrm{H}_{17} \mathrm{ClO}(\%)$ : C, 82.54; H, 4.36; Found: C, 82.48; H, 4.42.

14-(4-Bromophenyl)-14H-dibenzo[a,j]xanthenes: $\quad{ }^{1} \mathrm{H}$ NMR $\left(\mathrm{CDCl}_{3}\right): \delta 8.30(\mathrm{~s}, 1 \mathrm{H}), 8.28(\mathrm{~s}, 1 \mathrm{H}), 7.83(\mathrm{~s}, 1 \mathrm{H})$, $7.81(\mathrm{~s}, 1 \mathrm{H}), 7.79(\mathrm{~s}, 1 \mathrm{H}), 7.77(\mathrm{~s}, 1 \mathrm{H}), 7.56(\mathrm{t}, J=6.96 \mathrm{~Hz}$, 2H), 7.47 (s, 1H), $7.45(\mathrm{~s}, 1 \mathrm{H}), 7.42(\mathrm{~s}, 1 \mathrm{H}), 7.40(\mathrm{~s}, 1 \mathrm{H})$, $7.38(\mathrm{~s}, 1 \mathrm{H}), 7.36(\mathrm{~s}, 1 \mathrm{H}), 7.24(\mathrm{~d}, J=2.93 \mathrm{~Hz}, 2 \mathrm{H}), 6.43$ (s, $1 \mathrm{H}) ;{ }^{13} \mathrm{C}$ NMR: $148.66,143.95,131.55,131.22,131.03$, $129.83,129.07,128.88,126.88,124.34,122.36,120.18$, 117.97, 116.63, 37.41; IR (KBr, $\left.\mathrm{cm}^{-1}\right)$ : 3030, 1624, 1586.

\section{Results and discussion}

\subsection{Effect of catalyst concentration}

It had been experimentally shown that mono valent vanadyl cations could be substituted instead of the protons in the heteropolyacid structure [20]. It was also revealed in the same findings that vanadium did not change the structural framework of the acid, but strongly affected the physicochemical properties and catalytic activity of the Keggin heteropolyacid [20]. Presumably, the presence of strong acidic protons and the existence of an effective electron acceptor such as the vanadium atom in $\mathrm{H}_{5} \mathrm{PW}_{10} \mathrm{~V}_{2} \mathrm{O}_{40}$ would enhance the catalyst activity in these studies.

To understand the catalytic efficacy of $\mathrm{H}_{5} \mathrm{PW}_{10} \mathrm{~V}_{2} \mathrm{O}_{40}$, its activity was compared with structurally similar heteropolyacids in the preparation of 14-(4-chlorophenyl)-14Hdibenzo[a,j]xanthene. As shown in Table 1, different acidic and anionic heteropolyoxometalates were examined in different model reactions. The Heteropolyoxometalate catalysts introduced in Table 1 could be structurally divided into three important subclasses: Keggin, Wells-Dawson, and Preyssler. As shown in Table 1, both the Keggin and Wells-Dawson salts showed comparable catalytic activity; whereas, the Preyssler salt, $\mathrm{K}_{12.5} \mathrm{Na}_{1.5}\left[\mathrm{NaP}_{5} \mathrm{~W}_{30} \mathrm{O}_{110}\right]$, was inactive. Moreover, substitution of vanadium instead of $\mathrm{Mo}^{6+}$ and $\mathrm{W}^{6+}$ in the Keggin $\mathrm{H}_{3} \mathrm{PM}_{12} \mathrm{O}_{40}$ increased the catalytic activity of
Table 1 Effect of the kind of heteropolyacid catalyst in the synthesis of 14-(4-chlorophenyl)-14H-dibenzo[a,j]xanthene

\begin{tabular}{lcccc}
\hline Heteropolyacid & $\begin{array}{c}\text { Content } \\
(\%)\end{array}$ & $\begin{array}{c}\text { Time } \\
(\mathrm{min})\end{array}$ & $\begin{array}{c}\text { Yield } \\
(\%)\end{array}$ & $\begin{array}{c}\text { Selectivity } \\
(\%)\end{array}$ \\
\hline $\mathrm{H}_{5} \mathrm{PW}_{10} \mathrm{~V}_{2} \mathrm{O}_{40} \cdot x \mathrm{H}_{2} \mathrm{O}$ & 0.5 & 80 & 95 & 100 \\
$\mathrm{H}_{7} \mathrm{SiW}_{9} \mathrm{~V}_{3} \mathrm{O}_{40} \cdot x \mathrm{H}_{2} \mathrm{O}$ & 0.5 & 90 & 86 & $>98$ \\
$\mathrm{H}_{5} \mathrm{PMo}_{10} \mathrm{~V}_{2} \mathrm{O}_{40} \cdot x \mathrm{H}_{2} \mathrm{O}$ & 0.5 & 90 & 92 & $>98$ \\
$\mathrm{H}_{5} \mathrm{SiW}_{9} \mathrm{Mo}_{2} \mathrm{VO}_{40} \cdot x \mathrm{H}_{2} \mathrm{O}$ & 0.5 & 180 & 96 & 100 \\
$\mathrm{H}_{3} \mathrm{PMo}_{12} \mathrm{O}_{40} \cdot x \mathrm{H}_{2} \mathrm{O}$ & 0.5 & 100 & 90 & $>98$ \\
$\mathrm{~K}_{12.5} \mathrm{Na}_{1.5}\left[\mathrm{NaP}_{5} \mathrm{~W}_{30} \mathrm{O}_{110}\right] \cdot x \mathrm{H}_{2} \mathrm{O}$ & 0.5 & 480 & $<5$ & - \\
$\mathrm{H}_{6} \mathrm{P}_{2} \mathrm{~W}_{18} \mathrm{O}_{62} \cdot x \mathrm{H}_{2} \mathrm{O}$ & 0.5 & 90 & 92 & $>98$ \\
$\mathrm{H}_{3} \mathrm{PW}_{12} \mathrm{O}_{40} \cdot x \mathrm{H}_{2} \mathrm{O}$ & 0.5 & 80 & 86 & $>98$ \\
$\mathrm{H}_{3} \mathrm{PW}_{12} \mathrm{O}_{40} \cdot x \mathrm{H}_{2} \mathrm{O}$ & 2 & 60 & 92 & $>98$ \\
$\mathrm{H}_{3} \mathrm{PW}_{12} \mathrm{O}_{40} \cdot x \mathrm{H}_{2} \mathrm{O}$ & 5 & 30 & 98 & 100 \\
\hline
\end{tabular}

Reaction conditions: 2 mmol $\beta$-naphthol, $1 \mathrm{mmol}$ 4-chlorobenzaldehyde, $100{ }^{\circ} \mathrm{C}$, solvent free. The progress of the reactions was monitored as described in the experimental section by TLC. The product yield refers to isolated pure substance.

heteropolyacid. Di-vanado-tungsto(molybdo)phosphoric acids, $\mathrm{H}_{5} \mathrm{PW}_{10} \mathrm{~V}_{2} \mathrm{O}_{40}$ and $\mathrm{H}_{5} \mathrm{PMo}_{10} \mathrm{~V}_{2} \mathrm{O}_{40}$, indicated better catalytic activity than $\mathrm{H}_{3} \mathrm{PW}_{12} \mathrm{O}_{40}$ and $\mathrm{H}_{3} \mathrm{PMo}_{12} \mathrm{O}_{40}$. At the same time, $\mathrm{H}_{5} \mathrm{PW}_{10} \mathrm{~V}_{2} \mathrm{O}_{40}$ was a little more reactive than $\mathrm{H}_{5} \mathrm{PMo}_{10} \mathrm{~V}_{2} \mathrm{O}_{40}$.

Clearly, the nature and relative position of the constituent transition elements in the structural framework $\left[\mathrm{PM}_{12} \mathrm{O}_{40}\right]^{3-}$ ( $\mathrm{M}=\mathrm{W}$ or $\mathrm{Mo}$ ) strongly affected the acid-base and redox behavior of the Keggin type heteropoly anions at the atomic and molecular level [24,25]. As shown in Table 1, $\mathrm{H}_{3} \mathrm{PW}_{12} \mathrm{O}_{40}$ and $\mathrm{H}_{5} \mathrm{PW}_{10} \mathrm{~V}_{2} \mathrm{O}_{40}$ exhibited higher catalytic activity than molybdenum counterparts and might be attributed to the slightly higher acidity of the tungsten heteropolyacids. However, it should be mentioned that the present protocol was not entirely acid catalyzed. The effect of vanadium on the structure, acidity, and catalytic performance of heteropolyoxometallates had been studied extensively [26-28]. Particularly, it was found that acidity of heteropolyacids diminished by replacing $\mathrm{Mo}^{\mathrm{VI}}$ or $\mathrm{W}^{\mathrm{VI}}$ atoms with $\mathrm{V}^{\mathrm{V}}$ [29-31]. Although, $\mathrm{H}_{5} \mathrm{PW}_{10} \mathrm{~V}_{2} \mathrm{O}_{40}$ is considerably a weaker acid than $\mathrm{H}_{3} \mathrm{PW}_{12} \mathrm{O}_{40}$, it behaves better than $\mathrm{H}_{3} \mathrm{PW}_{12} \mathrm{O}_{40}$ and leads to $95 \%$ conversion rate after $80 \mathrm{~min}$.

It should be mentioned that substitution of two vanadium atoms in $\mathrm{H}_{3} \mathrm{PM}_{12} \mathrm{O}_{40}$ did not change the basic Keggin structure. Substitution of $\mathrm{P}^{\mathrm{V}}$ with $\mathrm{Si}^{\mathrm{IV}}$ in the vanadium substituted $\mathrm{H}_{5} \mathrm{PW}_{10} \mathrm{~V}_{2} \mathrm{O}_{40}$, led to the formation of less acidic $\mathrm{H}_{7} \mathrm{SiW}_{9} \mathrm{~V}_{3} \mathrm{O}_{40}$ heteropolyacid [32]. This compound was slightly less effective than the former and led to $86 \%$ yield after 90 min. $\mathrm{H}_{5} \mathrm{SiW}_{9} \mathrm{Mo}_{2} \mathrm{VO}_{40}$ as a mixed metal Si-substituted Keggin type heteropolyacid, showed distinctly low reactivity and resulted in $96 \%$ of the after 180 min. However, it was difficult to propose a clear mechanism for the different reactivity pattern observed for the heteropolyacids mentioned above. Undoubtedly, there is a com- 
plex relationship between the catalytic activity and structure of the polyanion. The acid strength of a heteropolyacid as well as its catalytic activity could be altered by changing the constituent hetero and addenda atoms of the polyanion. Obviously, substitution of molybdenum and tungsten with other transition metal cations strongly affected the catalytic properties of the Keggin heteropolyacids. In the case of vanadium, rebuilding of the heteropolyanion might occur and vanadyl salts would be formed during the catalytic route. The higher reactivity of $\mathrm{H}_{5} \mathrm{PW}_{10} \mathrm{~V}_{2} \mathrm{O}_{40}$ than $\mathrm{H}_{5} \mathrm{PMo}_{10} \mathrm{~V}_{2} \mathrm{O}_{40}$ could further be explained by considering structural reformation of the latter during reaction progress.

Optimization of the reaction conditions was performed by conducting the reaction of 4-chlorobenzaldehyde and $\beta$-naphthol using different amounts of $\mathrm{H}_{5} \mathrm{PW}_{10} \mathrm{~V}_{2} \mathrm{O}_{40}(0 \%$, $0.1 \%, 0.5 \%, 1 \%$, and $2 \%$ ) under solvent free condition at $100{ }^{\circ} \mathrm{C}$ (Table 2). The best results were obtained using $1 \%$ of $\mathrm{H}_{5} \mathrm{PW}_{10} \mathrm{~V}_{2} \mathrm{O}_{40}$ as optimum amount. Lower amounts of the catalyst decreased the conversion rate, whereas, higher amounts did not improve the reaction time and yield. Of note the product yield was found to be low in the absence of catalyst.

Table 2 Synthesis of 14-(4-chlorophenyl)-14H-dibenzo[a,j]xanthene using different amounts of $\mathrm{H}_{5} \mathrm{PW}_{10} \mathrm{~V}_{2} \mathrm{O}_{40}$ catalyst

\begin{tabular}{lcccc}
\hline Catalyst & $\begin{array}{c}\text { Content } \\
(\%)\end{array}$ & $\begin{array}{c}\text { Time } \\
(\mathrm{min})\end{array}$ & $\begin{array}{c}\text { Yield } \\
(\%)\end{array}$ & $\begin{array}{c}\text { Selectivity } \\
(\%)\end{array}$ \\
\hline $\mathrm{H}_{5} \mathrm{PW}_{10} \mathrm{~V}_{2} \mathrm{O}_{40}$ & - & 600 & 17 & $\sim 50$ \\
$\mathrm{H}_{5} \mathrm{PW}_{10} \mathrm{~V}_{2} \mathrm{O}_{40}$ & 0.1 & 540 & 79 & $>90$ \\
$\mathrm{H}_{5} \mathrm{PW}_{10} \mathrm{~V}_{2} \mathrm{O}_{40}$ & 0.5 & 80 & 95 & 100 \\
$\mathrm{H}_{5} \mathrm{PW}_{10} \mathrm{~V}_{2} \mathrm{O}_{40}$ & 1.0 & 30 & 98 & 100 \\
$\mathrm{H}_{5} \mathrm{PW}_{10} \mathrm{~V}_{2} \mathrm{O}_{40}$ & 2.0 & 30 & 97 & 100 \\
\hline
\end{tabular}

Reaction conditions were the same as in Table 1.

\subsection{Effect of solvent}

The condensation reaction to yield 14-(4-chlorophenyl)$14 \mathrm{H}$-dibenzo[a,j]xanthene was tested in different solvents such as ethanol, acetonitrile, ethyl acetate, and toluene, and the results were compared to the solvent free products. As shown in Table 3, the order of different solvents over product yield was as the follows of solvent free $>>$ ethyl acetate $>$ acetonitrile $>$ ethanol $\sim$ toluene. Since the more polar nature of the solvent is concentrated within the active centers of the catalyst, ethanol and acetonitrile were found to be more suitable to yield the desired xanthenedione. The less polar solvents such as toluene showed low product yield whereas dimethyl sulfoxide and dimethylformamide did not catalyze any reaction due to their nature to retard the condensation of the intermediates.

\subsection{Effect of reaction temperature}

Table 3 Effect of different solvents in the preparation of 14-(4-chlorophenyl)-14H-dibenzo[a,j]xanthene

\begin{tabular}{lccc}
\hline Solvent & Reflux temperature $\left({ }^{\circ} \mathrm{C}\right)$ & Time $(\mathrm{h})$ & Yield $(\%)$ \\
\hline Free & 100 & 1.3 & 95 \\
Ethanol & 80 & 16 & $<10$ \\
Acetonitrile & 90 & 8 & $<10$ \\
Ethyl acetate & 90 & 8 & 55 \\
Toluene & 120 & 13 & $<15$ \\
\hline
\end{tabular}

Reaction conditions were the same as in Table 1 and $0.5 \mathrm{~mol} \%$ $\mathrm{H}_{5} \mathrm{PW}_{10} \mathrm{~V}_{2} \mathrm{O}_{40}$ was used.

The effect of different temperatures on the reaction was also investigated for the synthesis of 14-(4-chlorophenyl)$14 \mathrm{H}$-dibenzo[a,j]xanthene in the presence of $\mathrm{H}_{5} \mathrm{PW}_{10} \mathrm{~V}_{2} \mathrm{O}_{40}$ $(0.5 \mathrm{~mol} \%)$ under solvent free condition (Fig. 1). The results revealed that percent yield was enhanced by increasing reaction temperature from 25 to $100{ }^{\circ} \mathrm{C}$ after $2 \mathrm{~h}$. The product (95\%) was obtained at $100^{\circ} \mathrm{C}$ after $80 \mathrm{~min}$, whereas, by decreasing the temperature to $80{ }^{\circ} \mathrm{C}$, the conversion was reduced to $90 \%$ after $2 \mathrm{~h}$. Even though, the maximum yield ( $>98 \%$ ) was obtained at temperatures higher than $100{ }^{\circ} \mathrm{C}$ during shorter times $(<1 \mathrm{~h}), 100{ }^{\circ} \mathrm{C}$ was selected as the optimum temperature for all the reactions.

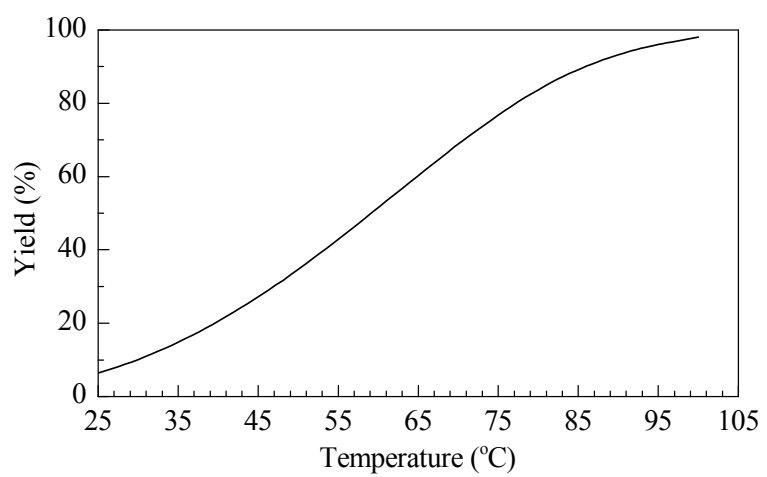

Fig. 1. Effect of reaction temperature on the preparation of 14-(4-chlorophenyl)-14H-dibenzo[a,j]xanthene after $2 \mathrm{~h}$.

\subsection{Condensation of different aromatic aldehydes with B-naphthol}

The applicability of the target protocol was demonstrated by applying a wide range of substituted aryl aldehydes to synthesize the corresponding products in high to excellent yields (Table 4). High yield transformations were achieved without any significant amounts of undesirable side products. Unlike some previously reported methods, the present method did not require toxic reagents or organic solvents to produce the aryl-14H-dibenzo[a,j]xanthene derivatives. A wide range of aromatic aldehydes was employed and all benzoxanthenes were obtained in high excellent yields based on the present general method that tolerated both electron-withdrawing and electron-donating constituents. 
Table 4 Synthesis of different xanthene derivatives catalyzed by $0.5 \mathrm{~mol}^{2} \mathrm{H}_{5} \mathrm{PW}_{10} \mathrm{~V}_{2} \mathrm{O}_{40}$

\begin{tabular}{|c|c|c|c|c|c|c|}
\hline \multirow{2}{*}{ Aldehyde } & \multirow{2}{*}{ Product } & \multirow{2}{*}{ Time (h) } & \multirow{2}{*}{ Yield (\%) } & \multicolumn{2}{|c|}{ Melting point $\left({ }^{\circ} \mathrm{C}\right)$} & \multirow{2}{*}{ Reference } \\
\hline & & & & Observed & Reported & \\
\hline & & $1(0.5)$ & $67(98)$ & $182-183$ & $181-183$ & [33] \\
\hline & & $0.8(0.5)$ & $72(98)$ & $212-213$ & $211-212$ & [33] \\
\hline & & $1(0.5)$ & $45(88)$ & 199-200 & - & - \\
\hline & & $1(0.5)$ & $40(91)$ & $295-297$ & 296 & [33] \\
\hline & & $1(40)$ & $40(92)$ & 309-310 & 310 & [34] \\
\hline & & $1(40)$ & $66(87)$ & 189-190 & $210-211$ & [35] \\
\hline & & $1.3(30)$ & $95(98)$ & 289-290 & $289-290$ & {$[33]$} \\
\hline & & $0.7(35)$ & $75(85)$ & 213-214 & 215 & [36] \\
\hline & & $1.2(50)$ & $35(82)$ & $190-91$ & 190-192 & [36] \\
\hline
\end{tabular}

Reaction conditions were the same as in Table 1, and $0.5 \% \mathrm{H}_{5} \mathrm{PW}_{10} \mathrm{~V}_{2} \mathrm{O}_{40}$ was used. All products were characterized by IR, ${ }^{1} \mathrm{H} \mathrm{NMR}$, melting point.

The current findings revealed that the reaction conditions were mild enough and did not damage moieties susceptible to cleavage in strongly acidic reaction media. The presence of electron-donating and electron-withdrawing groups in the aromatic ring of the aldehydes did not affect the reaction progress such that the respective xanthene derivatives were afforded in high yields. Therefore, the present method was general and included a variety of functional groups. However, para-substituted aldehydes resulted in better yields compared with the ortho-substituents, because of the more steric hindrances of the later.

\subsection{Advantages of $\mathrm{H}_{5} \mathrm{PW}_{10} \mathrm{~V}_{2} \mathrm{O}_{40}$ over some well-known high-valent metal/non-metal oxides}

Table 5 described the advantages of $\mathrm{H}_{5} \mathrm{PW}_{10} \mathrm{~V}_{2} \mathrm{O}_{40}$ in comparison with other catalysts used for the preparation of 14-(4-chlorophenyl)-14H-dibenzo[a,j]xanthene under the reported optimum reaction conditions. Evidently,
$\mathrm{H}_{5} \mathrm{PW}_{10} \mathrm{~V}_{2} \mathrm{O}_{40}$ is the best catalyst concerning catalyst content, reaction time, and yield. Among the examined additives, $\mathrm{ZrOCl}_{2}$ occupied the next position and $20 \%$ of this catalyst provided complete conversion after $1 \mathrm{~h}$. Meanwhile, $\mathrm{ZrCL}_{4}$ showed less activity and led to the same result under similar reaction condition after $2 \mathrm{~h}$, whereas, $\mathrm{ZrO}_{2}$ was in-

Table 5 Comparing the catalytic activity of $\mathrm{H}_{5} \mathrm{PW}_{10} \mathrm{~V}_{2} \mathrm{O}_{40}$ with some metal/non-metal oxides in the preparation of 14-(4-chlorophenyl)14H-dibenzo[a,j]xanthene.

\begin{tabular}{lcccc}
\hline Catalyst & Content (\%) & Time (h) & Yield (\%) & Selectivity (\%) \\
\hline- & - & 10 & 17 & $\sim 50$ \\
$\mathrm{H}_{5} \mathrm{PW}_{10} \mathrm{~V}_{2} \mathrm{O}_{40}$ & 0.5 & 1.3 & 95 & 100 \\
$\mathrm{ZrCL}_{4}$ & 20 & 2 & 99 & 100 \\
$\mathrm{ZrOCl}_{2}$ & 20 & 1 & 99 & 100 \\
$\mathrm{KH}_{2} \mathrm{PO}_{4}$ & 70 & 6 & 48 & $>70$ \\
$\mathrm{ZrO}_{2}$ & 20 & 9 & $<5$ & n.d. \\
$\mathrm{ZnO}$ & 20 & 18 & $<5$ & n.d. \\
$\mathrm{SiO}_{2}$ & 20 & 24 & $<5$ & n.d. \\
$\mathrm{Et}_{3} \mathrm{NHH}_{2} \mathrm{PO}_{4}$ & 50 & 6 & $<10$ & n.d. \\
\hline
\end{tabular}


Table 6 Comparison of the catalytic efficiency of $\mathrm{H}_{5} \mathrm{PW}_{10} \mathrm{~V}_{2} \mathrm{O}_{40}$ with some reported catalysts in synthesis of dibenzoxanthenes

\begin{tabular}{|c|c|c|c|c|c|}
\hline Catalyst & Catalyst (\%) & Time $(\mathrm{h})$ & Yield $(\%)$ & Condition & Reference \\
\hline $\mathrm{H}_{5} \mathrm{PW}_{10} \mathrm{~V}_{2} \mathrm{O}_{40}$ & 1 & $0.5-0.8$ & $82-98$ & solvent free, $100^{\circ} \mathrm{C}$ & this work \\
\hline SelectfluorTM $^{\mathrm{a}}$ & 10 & $6-12$ & $90-95$ & solvent free, $125^{\circ} \mathrm{C}$ & {$[37]$} \\
\hline Sulfamic acid & 10 & $6-12$ & $90-95$ & solvent free, $125^{\circ} \mathrm{C}$ & {$[39]$} \\
\hline $\mathrm{H}_{2} \mathrm{SO}_{4}: \mathrm{HOAc}$ & $1: 4(v: v)$ & 73 & $60-90$ & $\mathrm{HOAc}, 80^{\circ} \mathrm{C}$ & {$[40]$} \\
\hline $\mathrm{KAl}\left(\mathrm{SO}_{4}\right)_{2} \cdot 12 \mathrm{H}_{2} \mathrm{O}$ & 50 & $3-4$ & $82-91$ & $\mathrm{H}_{2} \mathrm{O}, 100^{\circ} \mathrm{C}$ & {$[41]$} \\
\hline $\mathrm{Sc}\left[\mathrm{N}\left(\mathrm{SO}_{2} \mathrm{C}_{8} \mathrm{~F}_{17}\right)_{2}\right]_{3}$ & 1 & $2-7$ & $70-96$ & perfluorodecalin, $110^{\circ} \mathrm{C}$ & {$[42]$} \\
\hline $\mathrm{Fe}\left(\mathrm{HSO}_{4}\right)_{3}$ & 10 & $1.2-6.5$ & $70-95$ & 1,2-dichloroethane (reflux) & {$[43]$} \\
\hline Montmorillonite K10 & $0.3 \mathrm{~g}$ & $2-4$ & $75-89$ & solvent free, $120^{\circ} \mathrm{C}$ & {$[44]$} \\
\hline $\mathrm{Yb}(\mathrm{OTf})_{3}$ & 1 & $3-7$ & $87-95$ & {$[$ bipy $] \mathrm{BF}_{4}, 110^{\circ} \mathrm{C}$} & {$[35]$} \\
\hline $\mathrm{FeCl}_{3}$ & 5 & 10 & $81-97$ & solvent free, $100{ }^{\circ} \mathrm{C}$ & {$[45]$} \\
\hline $\mathrm{RuCl}_{3} \cdot n \mathrm{H}_{2} \mathrm{O}$ & 10 & $1-4$ & $80-94$ & ethanol, $100^{\circ} \mathrm{C}$ & {$[46]$} \\
\hline Polystyrene/ $/ \mathrm{AlCl}_{3}$ & 20 & $1.5-4$ & $80-92$ & $\mathrm{CH}_{3} \mathrm{CN}$, reflux & {$[48]$} \\
\hline
\end{tabular}

${ }^{\mathrm{a}} 1$-(Chloromethyl)-4-fluoro-1,4-diazoniabicyclo[2.2.2]octane-bis(tetrafluoroborate).

effective. $\mathrm{KH}_{2} \mathrm{PO}_{4}(70 \%)$ also showed little catalytic activity and gave $48 \%$ of conversion after 6 . The ionic liquid $\left[\mathrm{Et}_{3} \mathrm{NH}\right] \mathrm{H}_{2} \mathrm{PO}_{4}, \mathrm{ZnO}$, and $\mathrm{SiO}_{2}$ were inefficient in the aforementioned catalytic transformation.

\subsection{Comparing the catalytic activity of $\mathrm{H}_{5} \mathrm{PW}_{10} \mathrm{~V}_{2} \mathrm{O}_{40}$ with other reported catalysts}

In order to further validate our work, the current protocol was compared with the data in the literature based on the catalysts content, temperature, reaction time, and percentage yields (Table 6). Although, some of the additives catalyzed the reaction at lower temperature, they required longer reaction times and/or higher catalyst content. Short-reaction time (30 $\mathrm{min}$ ), mild reaction condition, and environmentally benign catalyst are distinct advantages of the current methodology.

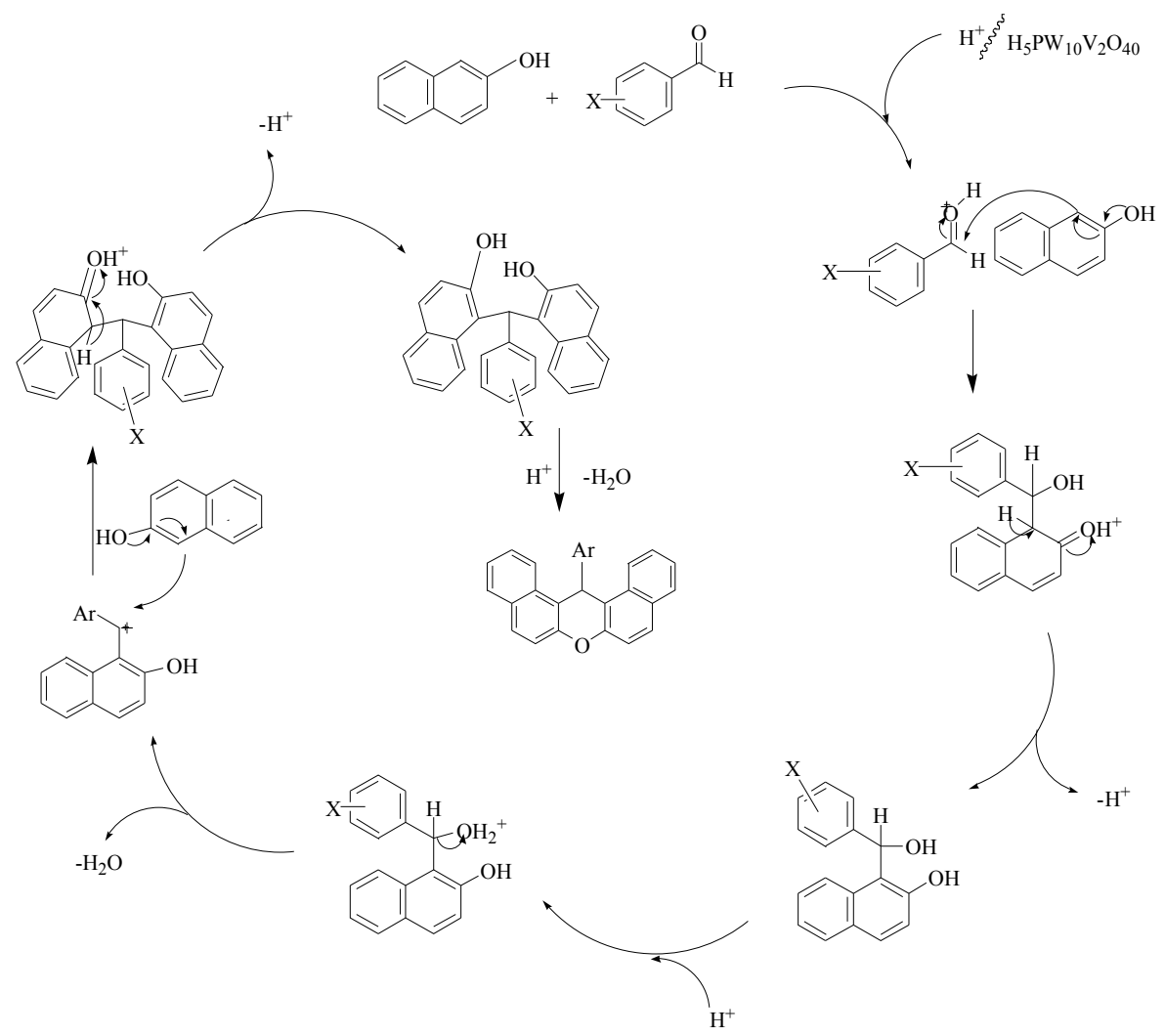

Scheme 2. Suggested reaction pathway for the catalytic synthesis of dibenzoxanthenes. 


\subsection{A plausible reaction pathway}

A scheme of the reported reaction mechanisms for the catalytic synthesis of dibenzoxanthenes [46] is outlined in Scheme 2. Activation of the carbonyl group of aldehyde by $\mathrm{H}_{5} \mathrm{PW}_{10} \mathrm{~V}_{2} \mathrm{O}_{40}$, facilitates nucleophilic attack of $\beta$-naphthol and formation of the corresponding carbocation in the first step. This carbocation was then transformed to an aryl-methanebisnaphthol in the second step, and ultimately it was converted to the desired product via dehydration of bis(naphtholyl)methane species.

\subsection{Spectroscopic evidence for the incorporation of vanadium into the Keggin structure and the stability of $\mathrm{H}_{5} \mathrm{PW}_{10} \mathrm{~V}_{2} \mathrm{O}_{40}$}

The specific structure of Keggin $\mathrm{H}_{5} \mathrm{PW}_{10} \mathrm{~V}_{2} \mathrm{O}_{40}$ gave rise to four types of oxygen atoms in the fingerprint region of IR spectrum in $700-1200 \mathrm{~cm}^{-1}$. These characteristic IR bands appeared at ca. $1088 \quad v(\mathrm{P}-\mathrm{O}), \quad 998 \quad v\left(\mathrm{~W}-\mathrm{O}_{\mathrm{d}}\right), \quad 890$ $v\left(\mathrm{~W}-\mathrm{O}_{\mathrm{b}}-\mathrm{M}\right)$, and $803 v\left(\mathrm{~W}-\mathrm{O}_{\mathrm{c}}-\mathrm{M}\right.$, where $\mathrm{M}=\mathrm{W}$ and $\left.\mathrm{V}\right)$ [49].

Comparison of the characteristic IR bands of $\mathrm{H}_{5} \mathrm{PW}_{10} \mathrm{~V}_{2} \mathrm{O}_{40}$ with those of $\mathrm{H}_{3} \mathrm{PW}_{12} \mathrm{O}_{40}$ (ca. 1075, 980, 885, and $810 \mathrm{~cm}^{-1}$ ) showed a slight shift to lower wave numbers. This shift is related to the influence of vanadium on the $\mathrm{W}-\mathrm{O}$ bond, and confirmed the entrance of vanadium into the primary structure of the Keggin anion [26]. Moreover, appearance of a broad $\mathrm{P}-\mathrm{O}_{\mathrm{i}}$ band in FT-IR spectrum of $\mathrm{H}_{5} \mathrm{PW}_{10} \mathrm{~V}_{2} \mathrm{O}_{40}$ confirmed the formation of vanadium included in the Keggin structure [50]. Furthermore, an intense charge-transfer UV-Vis absorption band at $\sim 200-300 \mathrm{~nm}$ appeared for various Keggin type heteropoly compounds, which was due to the charge-transfer of the terminal and bridged oxygen atoms that octahedrally surrounded the metal atoms ( $\mathrm{M}-\mathrm{O}$ and $\mathrm{V}-\mathrm{O})$ in the heteropoly cage $[51,52]$. The presence of vanadium in the Keggin structure resulted in broadening of the LMCT band [53].

The stability and deactivation of $\mathrm{H}_{5} \mathrm{PW}_{10} \mathrm{~V}_{2} \mathrm{O}_{40}$ under the reaction conditions were evaluated by reusing the recycled catalyst after completion of the first run. When the reaction was repeated using the recovered catalyst, the resultant conversion was close to the value obtained for the first run (Fig. 2). The Keggin structure for $\mathrm{H}_{5} \mathrm{PW}_{10} \mathrm{~V}_{2} \mathrm{O}_{40}$ could be used as an indicator for the stability and reusability of the catalyst. As shown in Fig. 3, the IR spectrum of the recovered $\mathrm{H}_{5} \mathrm{PW}_{10} \mathrm{~V}_{2} \mathrm{O}_{40}$ after the 9th run revealed that the Keggin structure was retained almost completely.

\section{Conclusions}

In this paper a highly efficient, one-pot, and green meth-

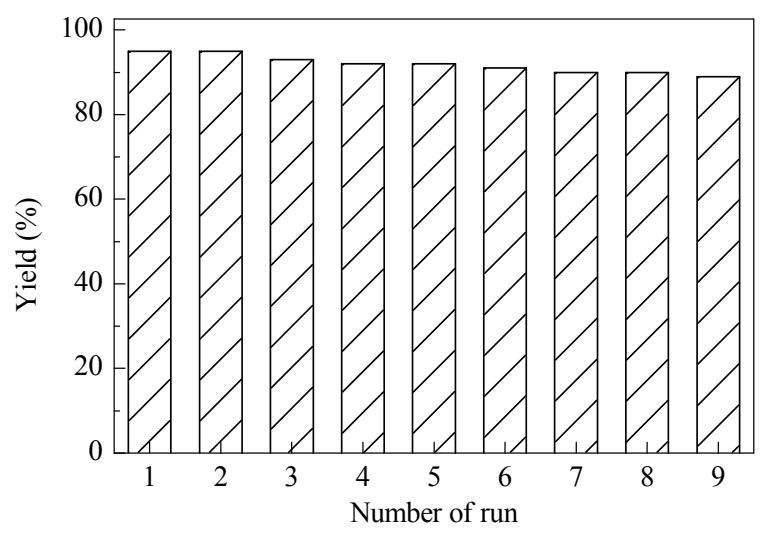

Fig. 2. Reusability of $\mathrm{H}_{5} \mathrm{PW}_{10} \mathrm{~V}_{2} \mathrm{O}_{40}$ in the synthesis of 14-(4-chlorophenyl)-14H-dibenzo[a,j]xanthene.

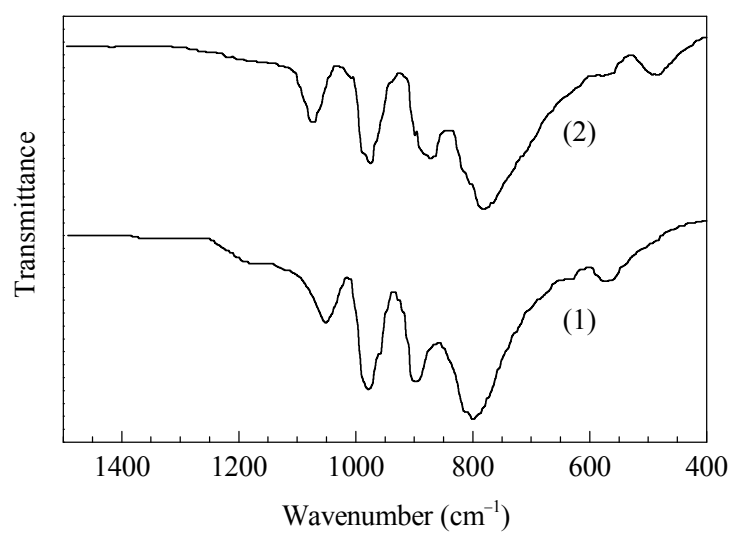

Fig. 3. FT-IR spectra of fresh (1) and recycled $\mathrm{H}_{5} \mathrm{PW}_{10} \mathrm{~V}_{2} \mathrm{O}_{40}$ after the 9 th run (2).

odology for the synthesis of aryl-14H-dibenzo[a,j]xan- thenes. The condensation of an aromatic aldehyde and $\beta$-naphthol in the presence of a catalytic amount of $\mathrm{H}_{5} \mathrm{PW}_{10} \mathrm{~V}_{2} \mathrm{O}_{40}$ under solvent free conditions was produced in excellent yields. The present methodology offers several advantages which include simple procedure, low cost, easy work-up, short reaction time, avoiding organic solvent, and using mild reaction conditions.

\section{Acknowledgements}

Partial financial support from the Research Council of Sabzevar Tarbiat Moallem University is greatly appreciated. Special thanks to Dr. Davoudi for English editing of the manuscript.

\section{References}

1 Hideo T. JP 56005 480. 1981

2 Saintruf G, Hieu H T, Poupelin J P. Naturwissenschaften, 1975, 62: 584

3 Ion R-M, Planner A, Wiktorowicz K, Frackowiak D. Acta 
Biochim Pol, 1998, 45: 833

4 El Ashry E S H, Awad L F, Ibrahim E S I, Bdeewy O K. ARKIVOC, 2006, (part 2): 178

5 Casiraghi G, Casnati G, Cornia M. Tetrahedron Lett, 1973, 14: 679

6 Bekaert A, Andrieux J, Plat M. Tetrahedron Lett, 1992, 33: 2805

7 Kuo C W, Fang J M. Synth Commun, 2001, 31: 877

8 Wang J Q, Harvey R G. Tetrahedron, 2002, 58: 5927

9 Jha A, Beal J. Tetrahedron Lett, 2004, 45: 8999

10 Timofeeva, M N. Appl Catal A, 2003, 256: 19

11 Thomas J M, Zamaraew K I eds. Perspective in Catalysis. London: Blackwell, 1992. 341

12 Nandhini K U, Arabindoo B, Palanichamy M, Murugesan V. J Mol Catal A, 2004, 223: 201

13 Tayebee R, Nehzata F, Rezaei-Sereshta E, Mohammadia F Z, Rafiee E. J Mol Catal A, 2011, 351: 154

14 Rezaei-Seresht E, Zonoz F, Estiri M, Tayebee R. Ind Eng Chem Res, 2011, 50: 1837

15 Tayebee R, Ghadamgahi M, Maleki B. Chin J Catal, 2012, 33: 659

16 Alizadeh M H, Tayebee R. J Braz Chem Soc, 2005, 16: 108

17 Tayebee R, Mahdavi B. Asian J Chem, 2009, 21: 1565

18 Okuhara T, Mizuno N, Misono M. Adv Catal, 1996, 41: 221

19 Rafiee E, Zolfagharifar Z, Joshaghani M, Eavani S. Appl Catal A, 2009, 365: 287

20 Bielanski A, Lubanska A. J Mol Catal A, 2004, 224: 179

21 Tsigdinos G A, Hallada C J. Inorg Chem, 1968, 7: 437

22 Karthikeyana G, Pandurangana A. J Mol Catal A, 2009, 311: 36

23 Shaterian H R, Ghashang M. J Braz Chem Soc, 2008, 19: 1053

24 Parida K M, Mallick S. J Mol Catal A, 2008, 279: 104

25 Misono M. Catal Rev Sci Eng, 1987, 29: 269

26 Casarini D, Centi G, Jiru P, Lena V, Tvaruzkova Z. J Catal, 1993, 143: 325

27 Nomiya K, Nemoto Y, Hasegawa T, Matsuoka S. J Mol Catal A, 2000, 152: 55

28 Nomiya K, Matsuoka S, Hasegawa T, Nemoto Y. J Mol Catal A, 2000, 156: 143

29 Jolivet J P. Metal Oxide Chemistry and Synthesis. Chichester: John Willey and Sons, 2000
30 Marcus R A. J Phys Chem, 1963, 67: 853

31 Marcus R A. Ann Rev Phys Chem, 1964, 15: 155

32 Weinstock I A. Chem Rev, 1998, 98: 113

33 Kumar R, Nandi G C, Verma R K, Singh M S. Tetrahedron Lett, 2010, 51: 442

34 Heravi M M, Bakhtiari K H, Darogheha Z, Bamoharram F F. J Mol Catal A, 2007, 273: 99

35 Su W, Yang D, Jin C, Zhang B. Tetrahedron Lett, 2008, 49: 3391

36 Rostamizadeh S H, Amani A M, Mahdavinia G, Shadjou N. Chin Chem Lett, 2009, 20: 779

37 Kumar P S, Kumar B S, Rajitha B, Reddy P N, Sreenivasulu N, Reddy Y T. ARKIVOC, 2006, (part 12): 46

38 Das B, Ravikanth B, Ramu R, Laxminarayana K, Vittal Rao B. J Mol Catal A, 2006, 255: 74

39 Rajitha B, Kumar B S, Reddy Y T, Reddy P N, Sreenivasulu N. Tetrahedron Lett, 2005, 46: 8691

40 Sarma R J, Baruah J B. Dyes Pigm, 2005, 64: 91

41 Dabiri M, Baghbanzadeh M, Shakouri Nikcheh M, Arzroomchilar E. Bioorg Med Chem Lett, 2008, 18: 436

42 Hong M, Cai C. J Fluor Chem, 2009, 130: 989

43 Eshghi H, Bakavoli M, Moradi H A. Chin Chem Lett, 2008, 19: 1423

44 Dabiri M, Azimi S C, Bazgir A. Chem Pap, 2008, 62: 522

45 Wang B, Li P H, Zhang Y, Wang L. Chin J Chem, 2010, 28: 2463

46 Tabatabaeian K, Khorshidi A, Mamaghani M, Dadashi A. Synth Commun, 2011, 41: 1427

47 Venu Madhav J, Suresh Kuarm B, Rajitha B. ARKIVOC, 2008, (ii): 204

48 Rahmatpour A, Aalaie J. Heteroatom Chem, 2011, 22: 51

49 Rocchiccioli-Deltcheff C, Fournier M, Franck R, Thouvenot R. Inorg Chem, 1983, 22: 207

50 Rocchiccioli-Deltcheff C, Fournier M. J Chem Soc, Faraday Trans, 1991, 87: 3913

51 He Z Q, Gao X H, Zhang P M, Xiao S X. J Chem Res Appl, 2001, 13: 253

52 Li L, Xu L, Wang Y X. Mater Lett, 2003, 57: 1406

53 Alekar N A, Halligudi S B, Rajani R, Gopinathan S, Gopinathan C. React Kinet Catal Lett, 2001, 72: 169 